OPEN ACCESS

Edited by:

Vincent Vander Poorten, KU Leuven, Belgium

Reviewed by: Alhadi Almangush,

University of Helsinki, Finland

Prasanth Penumadu,

Jawaharlal Institute of Postgraduate

Medical Education and Research

(JIPMER), India

*Correspondence:

Maria J. De Herdt

m.deherdt@erasmusmc.nl

${ }^{\dagger}$ These authors share last authorship

Specialty section:

This article was submitted to Head and Neck Cancer.

a section of the journal

Frontiers in Oncology

Received: 04 December 2020 Accepted: 06 April 2021

Published: 29 April 2021

Citation:

De Herdt MJ, van der Steen B, van der Toom QM, Aaboubout Y, Willems SM, Wieringa MH, Baantenburg de Jong RJ, Looijenga LHJ, Koljenović S and Hardillo JA (2021) The Potential of MET Immunoreactivity for Prediction of Lymph Node Metastasis in Early Oral Tongue Squamous Cell Carcinoma.

Front. Oncol. 11:638048. doi: 10.3389/fonc.2021.638048

\section{The Potential of MET} \section{Immunoreactivity for Prediction of} Lymph Node Metastasis in Early Oral Tongue Squamous Cell Carcinoma

\author{
Maria J. De Herdt ${ }^{1 *}$, Berdine van der Steen ${ }^{1}$, Quincy M. van der Toom ${ }^{1}$, Yassine Aaboubout ${ }^{1,2}$, \\ Stefan M. Willems ${ }^{3}$, Marjan H. Wieringa ${ }^{4}$, Robert J. Baatenburg de Jong ${ }^{1}$, \\ Leendert H. J. Looijenga ${ }^{2,5}$, Senada Koljenović ${ }^{2 \dagger}$ and Jose A. Hardillo ${ }^{1 \dagger}$ \\ 1 Department of Otorhinolaryngology and Head and Neck Surgery, Erasmus MC, University Medical Center Rotterdam, \\ Cancer Institute, Rotterdam, Netherlands, ${ }^{2}$ Department of Pathology and Medical Biology, Erasmus MC, University Medical \\ Center Rotterdam, Cancer Institute, Rotterdam, Netherlands, ${ }^{3}$ Department of Pathology, University Medical Center \\ Groningen, Groningen, Netherlands, ${ }^{4}$ Department of Education, Office of Science, Elisabeth TweeSteden, Ziekenhuis, \\ Tilburg, Netherlands, 5 Princess Maxima Center for Pediatric Oncology, Utrecht, Netherlands
}

Objective: MET positivity is independently associated with survival in oral squamous cell carcinoma (OSCC). Since MET is a known orchestrator of invasive tumor growth, we investigated its association with LNM in early oral tongue squamous cell carcinoma (OTSCC). As it is recommended by the NCCN to use tumor depth of invasion (DOI) in making decisions on elective neck dissection (END), the results obtained for MET positivity were aligned with those for $\mathrm{DOI}>4 \mathrm{~mm}$. The cutoff value used in our institution.

Methods: Tumor samples from patients who underwent primary tumor resection and neck dissection between 1995 and 2013, were collected from the archives of the Leiden and Erasmus University Medical Center. Immunohistochemistry with D1C2 was performed to identify MET negative $(<10 \%$ uniform positivity) and MET positive ( $\geq 10 \%$ uniform positivity) cancers. ROC curve analysis and the Chi-squared test were used to investigate the association of MET positivity with LNM ( $\mathrm{pN}+$ and occult). Binary logistic regression was used to investigate the association of MET positivity with LNM.

Results: Forty-five (44.1\%) of the 102 cancers were MET positive. Ninety were cNO of which 20 were $\mathrm{pN}+$ (occult metastasis). The remaining 12 cancers were $\mathrm{cN}+$, of which 10 were proven $\mathrm{pN}+$ and 2 were $\mathrm{pNO}$. MET positivity was associated with LNM with a positive predictive value (PPV) of $44.4 \%$ and a negative predictive value (NPV) of $82.5 \%$ for $\mathrm{pN}+$. For the occult group, the PPV was $36.8 \%$ and the NPV was $88.5 \%$. Regression analysis showed that MET positivity is associated with $\mathrm{pN}+$ and occult LNM ( $p$-value $<0.05)$.

Conclusion: MET positivity is significantly associated with LNM in early OTSCC, outperforming DOI. The added value of MET positivity could be in the preoperative setting when END is being considered during the initial surgery. For cases with $\mathrm{DOI} \leq$ $4 \mathrm{~mm}$, MET positivity could aid in the clinical decision whether regular follow-up, watchful waiting, or END is more appropriate. Realizing that these preliminary results need to be 
independently validated in a larger patient cohort, we believe that MET positivity could be of added value in the decision making on END in early OTSCC.

Keywords: MET, occult lymph node metastasis, depth of invasion, oral tongue squamous cell carcinoma, elective neck dissection

\section{INTRODUCTION}

Approximately one third of head and neck squamous cell carcinoma (HNSCC) originate in the oral cavity (OSCC) (1). For patients diagnosed with OSCC with clinically positive cervical lymph nodes, primary tumor resection with neck dissection is indicated. On the other hand, elective neck dissection (END) is recommended if the risk of occult lymph node metastasis (LNM) is 20\% (2). To date, tumor depth of invasion (DOI) is an established predictor for occult LNM and is recommended by the NCCN in making decisions on END (1).

Depth of invasion with a cut-off value $(>4 \mathrm{~mm})$ is a strong predictor for occult LNM, this cutoff value is therefore used within the Erasmus MC in making decisions on $\operatorname{END}(1,3,4)$. The DOI however is determined during the final pathological evaluation, days after the excision of the primary tumor (5). Therefore, cancers with DOI of $>4 \mathrm{~mm}$, would necessitate a second stage END resulting in additional morbidity for the patient, inefficient use of resources, time, and extra costs. Another downside of DOI is that it has been used interchangeably with tumor thickness, another predictor of LNM (6-9). This problem has been addressed in the $8^{\text {th }}$ edition of the AJCC that provides a clear definition for DOI (5).

In some centers, sentinel lymph node biopsy (SLNB) is being performed to rule out the presence of occult LNM. With detection rates of $95 \%$ (10-12), 0.93 sensitivity and NPV of 0.88 to 1 (11-15), SLNB is a reliable method to detect occult LNM during surgery. However, the success rate of SLNB depends on the experience and technical expertise of the team performing the procedure making the implementation of SLNB in routine patient care difficult (1).

It is clear, that there still is a need for reliable preoperative predictors of occult LNM that can further improve the decision making process on END. Ideally, such predictors should be easily incorporated in a routine diagnostic setting.

A target of interest is the receptor tyrosine kinase MET (16). Using a novel scoring system, it was shown that MET positivity is associated with poor overall survival (OS) and disease-free survival (DFS) in OSCC (17). Amongst its pleiotropic functions as an oncogene, MET orchestrates the program of invasive growth $(16,18,19)$. As MET facilitates the dissemination of cancers cells, it is an interesting target for the prediction of LNM.

This study investigated whether MET positivity is associated with LNM (pN+ and occult) in early oral tongue SCC (OTSCC). This association was compared with DOI $>4 \mathrm{~mm}$, a known predictor of occult LNM. We further, hypothesized on the potential added value of MET positivity in the clinical decision-making on END.

\section{MATERIALS AND METHODS}

\section{Ethics Statement}

Human tissues and patient data were used according to "The Code of Conduct for Responsible Use" and "The Code of Conduct for Health Research" as stated by the Federation of Dutch Medical Scientific Societies (20). Furthermore, The Erasmus MC Medical Ethics Committee approved the research protocol (MEC-2016-751).

\section{Study Design, Patient, and Tumor Characteristics}

Inclusion criteria were patients with early OTSCC (pT1-2) treated primary with surgery with a neck dissection, at the Leiden University Medical Center (LUMC, between 1995 and 2010) and the Erasmus MC Cancer Institute (Erasmus MC, between 2006 and 2013).

All patient and tumor characteristics, except the DOI, were retrieved from the patient files including: gender, age, tumor diameter $(\mathrm{cm})$, TNM (21), extranodal extension (21), and margin status $(21,22)$. The DOI was measured according to the guidelines of the 8th edition of the AJCC (5). HE sectionsmade for diagnostic assessment-were retrieved from the archives and scanned using the NanoZoomer 2.0-HT slide scanner (Hamamatsu Photonics, Hamamatsu, Japan). Other tumor characteristics (i.e. degree of differentiation, pattern of invasion, lymphovascular invasion, perineural invasion, and data on postoperative radiotherapy) were not further recorded or analyzed in this study.

Follow-up data in respect to OS and DFS were also recorded.

A previous history of head and neck cancer was a reason for exclusion.

\section{Tissues, Antibody, and Immunohistochemistry}

Formalin-fixed paraffin-embedded tissue blocks representative of the included cancers were retrieved from the tissue banks of the departments of pathology from both medical centers. Using a microtome, $3 \mu \mathrm{m}$ thick whole tissue sections were cut for immunohistochemical analyses.

D1C2 (Cell Signaling Technology ${ }^{\circledR}$; Danvers, MA, USA) was used to detect C-terminal MET immunoreactivity according to the method described in our previous publications $(17,23)$.

Membranous immunoreactivities obtained using D1C2 were characterized by assessing for four staining patterns: uniform negative, gradient toward the periphery, uniform positive, and gradient toward the center according to the scoring system described in our previous publication (Figure 1) (17). 


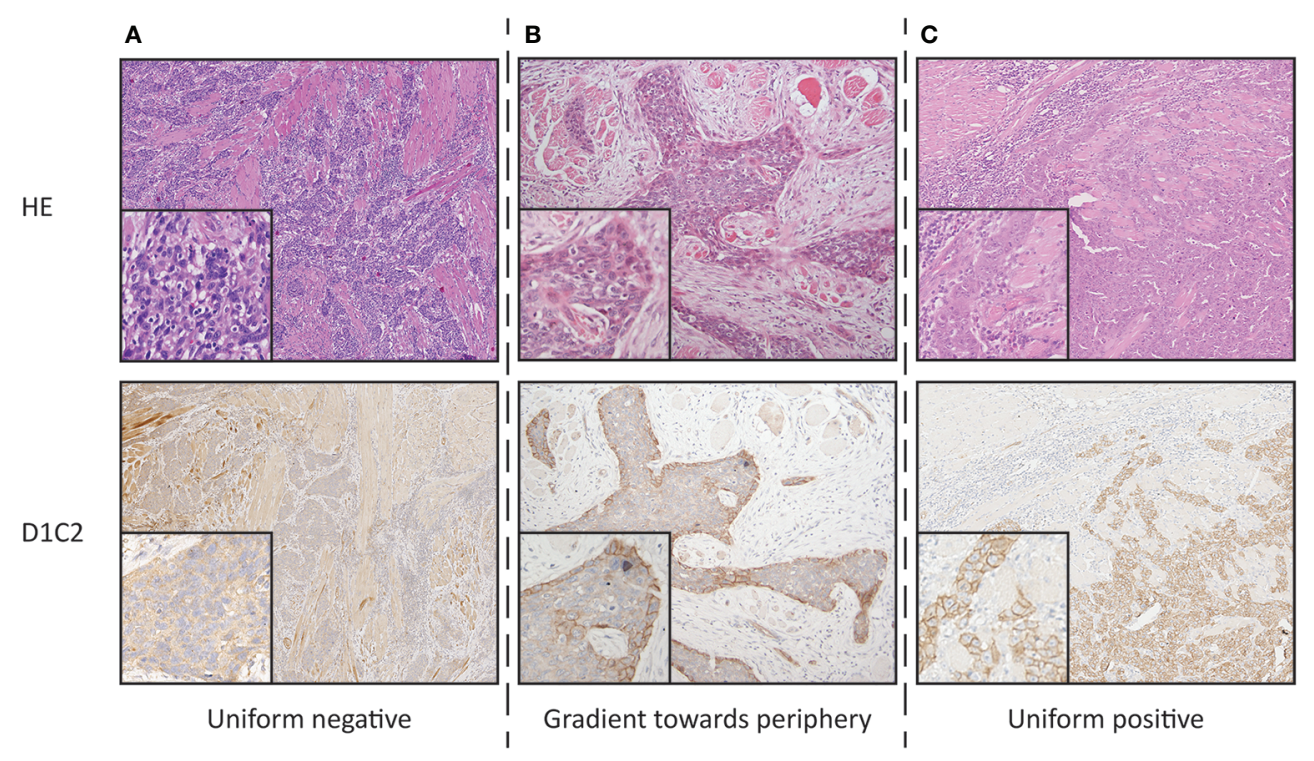

FIGURE 1 | Photographs representing the defined staining patterns observed using D1C2 and corresponding HE section (10x and 20x objective). (A) Uniform negative (B) Gradient toward periphery. (C) Uniform positive. The gradient toward center staining pattern was not observed.

\section{Association of MET Positivity and DOI With LNM}

Analogous to the known association of $\geq 10 \%$ of the D1C2 uniform positive staining pattern with OS and DFS, it was assessed if $\geq 10 \%$ D1C2 uniform positivity (further on referred to as MET positivity) is associated with histopathologically proven LNM $(\mathrm{cN} 0 / \mathrm{pN}+$ and $\mathrm{cN}+/ \mathrm{pN}+)$ and occult LNM $(\mathrm{cN0} / \mathrm{pN}+)$ using receiver operating characteristic (ROC) curve analysis (17).

The DOI cutoff value $>4 \mathrm{~mm}$ used in the Erasmus MC as an indication for END, was investigated by assessing the association between DOI $>4 \mathrm{~mm}$ and proven as well as occult LNM using ROC curve analysis (1).

\section{STATISTICAL ANALYSES}

The Chi-squared test, non-parametric Fisher's exact test and independent-Samples T-test were used to compare the patient and tumor characteristics of the LUMC and Erasmus MC cohorts.

To calculate the proportion of MET positive cancers within the whole $\mathrm{pN}+$ group (occult and overt LNM), the Chi-squared test was used. The same was done for DOI $>4 \mathrm{~mm}$.

To calculate the proportion of MET positive cancers within the occult LNM group $(\mathrm{cN} 0 / \mathrm{pN}+)$, the Chi-squared test was used. The same was done for DOI $>4 \mathrm{~mm}$.

Binary logistic regression was performed to investigate whether MET positivity and/or DOI have a-joint-effect on LNM.

Calculations were performed with SPSS Statistics (version 25; IBM; Armonk, NY, USA). Unless otherwise mentioned, statistical significance was set at $p$-value $<0.05$.

\section{RESULTS}

\section{Comparison of the LUMC and Erasmus MC Patient and Tumor Characteristics}

The 102 patients included in this study were treated for primary pT1-2 OTSCC with surgery and-if indicated-postoperative radiotherapy in the LUMC or Erasmus MC across different periods. Twenty-five $(24.5 \%)$ patients were treated in the LUMC and $77(75.5 \%)$ in the Erasmus MC. Comparison of the patient and tumor characteristics as well as MET positivity shows that there are no differences between the two centers (Supplementary Table 1). OS and DFS were also similar (results not shown).

\section{Association of MET Positivity and DOI With LNM in D1C2 Positive Cancers}

Hundred and two (102) patients were treated with tumor resection and a neck dissection. Thirty (29.4\%) were pN+, of which 20 (66.7\%) were $\mathrm{cN0}$ and therefore occult metastases (Table 1).

ROC curve analyses showed that MET positivity is associated with $\mathrm{pN}+$ and occult LNM and that DOI $>4 \mathrm{~mm}$ has a higher sensitivity for $\mathrm{pN}+$ and occult LNM compared to MET positivity (Figure 2, Supplementary Figure 1).

Forty-five $(44.1 \%)$ of the included cancers were positive for MET (Table 2). Seventy-five cancers (73.5\%) had a DOI > $4 \mathrm{~mm}$ (Table 3). The positive predictive value (PPV) for MET positivity was $44.4 \%$, for DOI $>4 \mathrm{~mm} \mathrm{33.3 \%}$ (Table 4). The NPV for MET positivity was $82.5 \%$, for DOI $>4 \mathrm{~mm} 81.5 \%$ (Table 4). Within the $\mathrm{cN} 0$ group ( $\mathrm{n}=90), 38$ cancers were positive for MET $(42.2 \%)$ (Table 2) and 52 had a DOI $>4 \mathrm{~mm}(57.8 \%)$ (Table 3). For this cN0 group, the PPV for MET positivity was $36.8 \%$, for DOI > $4 \mathrm{~mm} 25.8 \%$; the NPV for MET positivity was $88.5 \%$ and for DOI $>4 \mathrm{~mm} 87.5 \%$ (Table 4 ). 
TABLE 1 | Presentation of pathological lymph node groups $(\mathrm{pN})$ with respect to clinical lymph node groups (cN).

\begin{tabular}{lcccc}
\hline & & \multicolumn{2}{c}{$\mathbf{c N}$} & Total \\
\cline { 3 - 4 } & & $\mathbf{N}$ & $\mathbf{N +}$ & \\
\hline $\mathrm{pN}$ & $\mathrm{N} 0$ & 70 & 2 & 72 \\
& $\mathrm{~N}+$ & 20 & 10 & 30 \\
Total & & 90 & 12 & 102 \\
\hline
\end{tabular}

\section{MET Positivity and DOI as Predictors for (pN+ and Occult) LNM}

Univariable binary logistic regression showed that MET positivity is associated with $\mathrm{pN}+$ status in general $(\mathrm{OR}=3.76$; 95\% CI: 1.53-9.26, $p$-value $<0.05$; Supplementary Table 2 ) and for occult $\operatorname{LNM}(\mathrm{OR}=4.28$; 95\% CI: $1.45-12.65$, $p$-value $<0.05$;
Supplementary Table 2). DOI $>4 \mathrm{~mm}$ shows an OR of 2.20 for pN+ (95\% CI: 0.745-6.50, $p$-value $=0.15$; Supplementary Table 3 ) and 2.43 for occult LNM (95\% CI: 0.64-9.18, $p$-value = 0.19; Supplementary Table 3). Multivariable analysis showed that MET positivity is independently associated with $\mathrm{pN}+$ in general and occult LNM when corrected for DOI $>4 \mathrm{~mm}$ (Table 5).

A $2 \times 2$ table for $\mathrm{pN}+$ cancers $(\mathrm{n}=30)$, depicting the number of cancers either negative ( $<10 \%$ uniform positivity) or positive for MET versus DOI $\leq$ or $>4 \mathrm{~mm}$, illustrates that there were 2 (6.67\%) MET negative cancers with LNM in the group DOI $\leq$ $4 \mathrm{~mm}$. Three (10.0\%) cancers with LNM were MET positive and had a DOI $\leq 4 \mathrm{~mm}$. Eight (26.7\%) cancers with LNM were MET negative and had a DOI $>4 \mathrm{~mm}$. Seventeen (56.7\%) cancers with LNM were MET positive and had a DOI $>4 \mathrm{~mm}$ (Table 6). A similar $2 \times 2$ table for cases with occult LNM $(n=20)$ shows 1 (5.00\%) MET negative cancer with occult LNM with DOI $\leq$

\section{A}

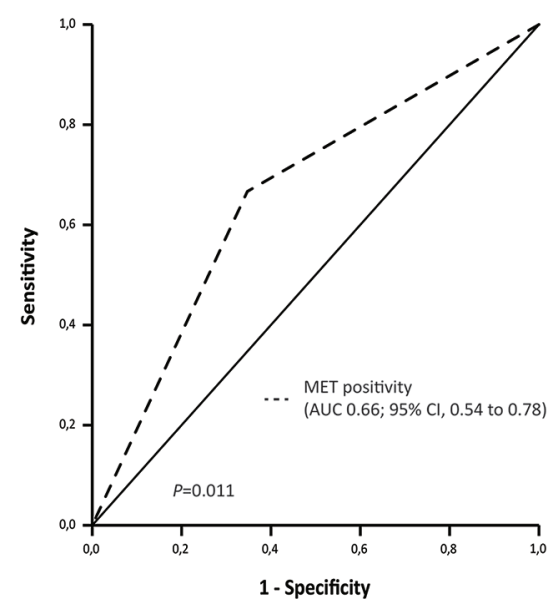

B

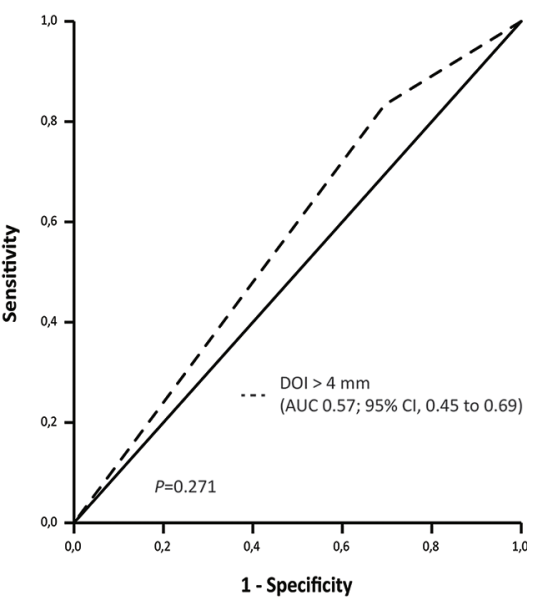

FIGURE 2 | ROC curve indicating the area under the curve for (A) MET positivity and (B) Depth of invasion set at > 4 mm and LNM (cNO and cN+/pN+).

TABLE 2 | Cross-tabulations showing the relationship between MET positivity and pN status in all cancers ( $\mathrm{n}=102)$ and in cN0 cancers ( $\mathrm{n}=90)$.

\begin{tabular}{|c|c|c|c|c|c|c|}
\hline \multirow[t]{2}{*}{ MET positivity } & \multicolumn{3}{|c|}{ All patients $(n=102)$} & \multicolumn{3}{|c|}{ cNO patient $(n=90)$} \\
\hline & $\mathrm{pN}+$ & pNO & Row total & $\mathrm{pN}+$ & pNO & Row total \\
\hline Yes & 20 (66.7\%) & 25 (34.7\%) & $45(44.1 \%)$ & 14 (70.0\%) & 24 (34.3\%) & 38 (42.2\%) \\
\hline No & 10 (33.3\%) & 47 (65.3\%) & 57 (55.9\%) & 6 (30.0\%) & $46(65.7 \%)$ & $52(57.8 \%)$ \\
\hline Column total & 30 (100\%) & 72 (100\%) & 102 (100\%) & 20 (100\%) & 70 (100\%) & 90 (100\%) \\
\hline Significance & \multicolumn{3}{|c|}{$p$-value $=0.003$} & \multicolumn{3}{|c|}{$p$-value $=0.004$} \\
\hline
\end{tabular}

TABLE 3 | Cross-tabulations showing the relationship between DOI and pN status in all cancers ( $\mathrm{n}=102)$ and in cN0 cancers ( $\mathrm{n}=90)$.

DOI

\begin{tabular}{lc}
\cline { 2 - 2 } & $\mathbf{p N}+$ \\
\hline$>4 \mathrm{~mm}$ & $25(83.3 \%)$ \\
$\leq 4 \mathrm{~mm}$ & $5(16.7 \%)$ \\
Column total & $30(100 \%)$ \\
Significance &
\end{tabular}

All patients $(n=102)$

$\begin{array}{cc}\text { pNo } & \text { Row total } \\ 50(69.4 \%) & 75(73.5 \%) \\ 22(30.6 \%) & 27(26.5 \%) \\ 72(100 \%) & 102(100 \%) \\ p \text {-value }=0.147 & \end{array}$

cNO patient $(n=90)$

\begin{tabular}{ccc}
\hline $\mathbf{p N}+$ & pNo & Row total \\
\hline $17(85.0 \%)$ & $49(70.0 \%)$ & $66(73.3 \%)$ \\
$3(15.0 \%)$ & $21(30.0 \%)$ & $24(26.7 \%)$ \\
$20(100 \%)$ & $70(100 \%)$ & $90(100 \%)$
\end{tabular}


TABLE 4 | Sensitivity, specificity, PPV, and NPV and accuracy of MET positivity and DOI > 4 mm with respect to pN+ for all cancers ( $\mathrm{n}=102)$ and cNO cancers ( $\mathrm{n}=90$ ).

\begin{tabular}{|c|c|c|c|c|c|c|c|c|c|c|}
\hline & \multicolumn{5}{|c|}{ All patients $(n=102)$} & \multicolumn{5}{|c|}{ cN0 patients $(n=90)$} \\
\hline & Sens. (\%) & Spec. (\%) & PPV (\%) & NPV (\%) & Acc. (\%) & Sens. (\%) & Spec. (\%) & PPV (\%) & NPV (\%) & Acc. (\%) \\
\hline MET positivity & 66.7 & 65.3 & 44.4 & 82.5 & 65.7 & 70.0 & 65.7 & 36.8 & 88.5 & 66.7 \\
\hline $\mathrm{DOI}>4 \mathrm{~mm}$ & 83.3 & 30.6 & 33.3 & 81.5 & 46.1 & 85.0 & 30.0 & 25.8 & 87.5 & 42.2 \\
\hline
\end{tabular}

TABLE 5 | Multivariable binary logistic regression model investigating the independent effect of MET positivity and DOI > 4 mm on pN+ for all cancers ( $\mathrm{n}=102)$ and cNO cancers $(n=90)$.

\begin{tabular}{|c|c|c|c|c|c|c|}
\hline \multirow[t]{2}{*}{ Variable } & \multicolumn{3}{|c|}{ All patients $(n=102)$} & \multicolumn{3}{|c|}{ cN0 patient $(n=90)$} \\
\hline & Odds ratio & $95 \% \mathrm{Cl}$ & $p$-value & Odds ratio & $95 \% \mathrm{Cl}$ & $p$-value \\
\hline MET positivity & 3.66 & $1.47-9.06$ & 0.005 & 4.28 & $1.45-12.65$ & 0.009 \\
\hline $\mathrm{DOI}>4 \mathrm{~mm}$ & 2.05 & $0.67-6.30$ & 0.209 & 2.16 & $0.55-8.53$ & 0.274 \\
\hline Constant & 0.12 & & 0.000 & 0.073 & & 0.000 \\
\hline Significance & \multicolumn{3}{|c|}{$p$-value $=0.005$} & \multicolumn{3}{|c|}{$p$-value $=0.009$} \\
\hline
\end{tabular}

$4 \mathrm{~mm}$. Two (10.0\%) cancers with occult LNM were MET positive and had a DOI $\leq 4 \mathrm{~mm}$. Five $(25.0 \%)$ cancers with occult LNM were MET negative and had a DOI > $4 \mathrm{~mm}$. Twelve $(60.0 \%)$ cancers with occult LNM were MET positive and had a DOI > $4 \mathrm{~mm}$ (Table 6). These numbers illustrated the potential additive value of MET positivity to DOI $>4 \mathrm{~mm}$ to assess the presence of LNM ( $\mathrm{pN}+$ and occult).

\section{DISCUSSION}

For patients with early OSCC, END is generally recommended when the chance of occult lymph node metastasis is more than $20 \%(2,4,24-26)$. DOI is one of the most reliable parameters to predict occult LNM and guide clinical decision making on END. At our center DOI cut-off value $>4 \mathrm{~mm}$ is used. DOI is usually determined days after initial surgery based on the final histopathological assessment. As such, END is often performed during second surgery when DOI is $>4 \mathrm{~mm}$. There is a need for reliable measurement of DOI before initial cancer surgery for example in biopsies. However, DOI measured on diagnostic biopsies is not reliable as sampling may not be representative of the entire primary cancer $(24,27)$. Assessment of DOI by preoperative MRI or intraoral ultrasonography is an alternative. However, preoperative MRI has been reported to be not accurate in tumors with DOI $<5 \mathrm{~mm}(28-33)$. Another alternative is measuring DOI during specimen-driven intraoperative assessment using frozen sections (34-36). This would enable an elective END during initial surgery in $\mathrm{cN0}$ cases with DOI >

TABLE 6 | $2 \times 2$ tables showing the relationship between MET positivity and $\mathrm{DOI}$ status in cancers with $\mathrm{pN}+(\mathrm{n}=30)$ and cancers with occult $\mathrm{LNM}(\mathrm{n}=20)$.

\begin{tabular}{|c|c|c|c|c|}
\hline & \multicolumn{2}{|c|}{ Cancers with $\mathrm{pN}+(\mathrm{n}=30)$} & \multicolumn{2}{|c|}{ Cancers with occult LNM $(n=20)$} \\
\hline & $\mathrm{DOI} \leq 4 \mathrm{~mm}$ & $\mathrm{DOI}>4 \mathrm{~mm}$ & $\mathrm{DOI} \leq 4 \mathrm{~mm}$ & $\mathrm{DOI}>4 \mathrm{~mm}$ \\
\hline MET negative & 2 (6.67\%) & 8 (26.7\%) & 1 (5.00\%) & 5 (25.0\%) \\
\hline MET positive & $3(10.0 \%)$ & $17(56.7 \%)$ & $2(10.0 \%)$ & $12(60.0 \%)$ \\
\hline
\end{tabular}

$4 \mathrm{~mm}$. Although promising, further validation and optimization is necessary to implement intraoperative assessment of DOI using frozen sections in a routine diagnostic setting. However, intraoperative assessment of DOI also has its limitations entailing patient uncertainty concerning the decision on END prior to surgery and the unnecessary prescheduled OR time for all potential ENDs leading to inefficiency and additional costs. Moreover, the direct communication that is necessary between surgeon and pathologist is not always possible $(24,36)$.

The current study shows that MET positivity is univariably associated with LNM in OTSCC. This result was expected given the established association of MET positivity with OS and DFS in OSCC $(17,23)$. The result also concurs with the fact that wildtype MET activity is known to increase cell death, invasion and distant metastasis (18).

Receptor tyrosine kinase MET is a known orchestrator of invasive growth $(16,19,37,38)$. As LNM is one of the major determinants of patient outcome in HNSCC, we are not the first to investigate the association between MET expression and LNM. It has been shown that expression levels of MET are high in cancer tissues and in corresponding affected lymph nodes (39-41). Additionally, it was shown that the MET gene product is more sensitive in the detection of occult LNM compared to cytokeratins in OSCC (42).

The PPV of MET on occult LNM was $36.8 \%$, which meets the recommendation of performing an END if the risk of occult LNM is $20 \%$ (NPV $80 \%$ ) (2). In this study, we also showed that MET positivity has a NPV of $88.5 \%$ for occult LNM. Depth of invasion $>4 \mathrm{~mm}$ is a known predictor for occult LNM (4), in accordance with our results (PPV 25.8\%). The established PPVs of MET positivity and DOI $>4 \mathrm{~mm}$ showed that MET outperforms DOI in predicting occult LNM. Multivariable analysis showed that only MET positivity is independently associated with LNM, pN+ and occult ( $p$-value < 0.05). Although DOI $>4 \mathrm{~mm}$ did not significantly contribute to the multivariable model, it showed a strong relation with $\mathrm{pN}+\mathrm{LNM}$ $(\mathrm{OR}=2.05, p$-value $=0.209)$ and occult LNM $(\mathrm{OR}=2.16$, $p$-value $=$ 0.274 ). The lack of significance of DOI $>4 \mathrm{~mm}$ can probably be 
explained by the low number of cases with DOI $\leq 4 \mathrm{~mm}$. These results suggest that MET positivity might also be of value in predicting the presence or absence of occult LNM in the preoperative setting, and besides DOI, in the postoperative setting (after removal of the primary tumor) in early OTSCC.

We foresee that performing routine immunohistochemistry using the D1C2 antibody against the C-terminus of MET on biopsies, could be of great value in deciding when and when not to perform an END during the initial OTSCC surgery. This would improve logistics, cost-effectiveness, and would reduce patient morbidity caused by two separate surgeries. This study is performed on whole tissue sections, therefore efforts have to be made to design a future study to extrapolate these results to biopsies. To anticipate for cancer heterogeneity we expect that (preoperative) biopsies will need to be taken from the center and periphery of the cancer (17).

The fact that there were less occult LNMs for cancers negative for MET and with DOI $\leq 4 \mathrm{~mm}$ compared to cancers positive for MET and with DOI $\leq 4 \mathrm{~mm}$, illustrates that MET positivity could be of added value to DOI $\leq 4 \mathrm{~mm}$ for the clinical decision on the treatment of the cN0 neck i.e., whether regular follow-up, watchful waiting, or END is more appropriate. We can imagine that patients with MET positive cancers and DOI $\leq$ $4 \mathrm{~mm}$ could have more stringent follow-up than patients in the same DOI group but with MET negative cancers. We realize that this statement is based on very low numbers and independent validation is necessary.

Taking into account that the obtained results are preliminary and need to be independently validated in a larger and more recent patient cohort incorporating both patients that underwent END and watchful waiting and containing detailed registration of relevant histopathological parameters, we believe that MET positivity could be of added value in pre- and postoperative (after primary tumor resection) decision making on END in early OTSCC.

\section{DATA AVAILABILITY STATEMENT}

The raw data supporting the conclusions of this article will be made available by the authors, without undue reservation.

\section{REFERENCES}

1. National Comprehensive Cancer Network. Nccn Clinical Practice Guidelines in Oncology (Nccn Guidelines) Head and Neck Cancers Version 2.2020 (2020). Available at: https://www.nccn.org/store/login/login.aspx?ReturnURL= https://www.nccn.org/professionals/physician_gls/pdf/head-and-neck.pdf.

2. Weiss MH, Harrison LB, Isaacs RS. Use of Decision Analysis in Planning a Management Strategy for the Stage N0 Neck. Arch Otolaryngol Head Neck Surg (1994) 120(7):699-702. doi: 10.1001/archotol.1994.01880310005001

3. Aaboubout Y, van der Toom QM, de Ridder MAJ, De Herdt MJ, van der Steen B, van Lanschot CGF, et al. Is the Depth of Invasion a Marker for Elective Neck Dissection in Early Oral Squamous Cell Carcinoma? Front Oncol (2021) 11:628320. doi: 10.3389/fonc.2021.628320

4. van Lanschot CGF, Klazen YP, de Ridder MAJ, Mast H, Ten Hove I, Hardillo JA, et al. Depth of Invasion in Early Stage Oral Cavity Squamous Cell Carcinoma: The Optimal Cut-Off Value for Elective Neck Dissection. Oral Oncol (2020) 111:104940. doi: 10.1016/j.oraloncology.2020.104940

\section{ETHICS STATEMENT}

Human tissues and patient data were used according to "The Code of Conduct for Responsible Use" and "The Code of Conduct for Health Research" as stated by the Federation of Dutch Medical Scientific Societies. Furthermore, The Erasmus MC Medical Ethics Committee approved the research protocol (MEC-2016-751).

\section{AUTHOR CONTRIBUTIONS}

MD: conceptualization, methodology, software, formal analysis, data curation, writing - original draft, and visualization. BV: investigation, data curation, writing-review and editing, and visualization. QV: data curation and writing-review and editing. YA: data curation and writing - review and editing. SW: writing-review and editing. MW: methodology and writing-review and editing. RB: writingreview and editing. LL: writing-review and editing. SK: conceptualization, methodology, writing-review and editing, and supervision. JH: conceptualization, methodology, writing-review and editing, and supervision. All authors contributed to the article and approved the submitted version.

\section{ACKNOWLEDGMENTS}

The authors thank all the head and neck surgeons of the Leiden University Medical Center for facilitating the use of their follow-up data. The authors also thank Prof. Dr. Vincent Smit of the Leiden University Medical Center for facilitating the use of the representative resection specimens, his guidance, and critical feedback.

\section{SUPPLEMENTARY MATERIAL}

The Supplementary Material for this article can be found online at: https://www.frontiersin.org/articles/10.3389/fonc.2021. 638048/full\#supplementary-material

5. American Joint Commity on Cancer. Ajcc Cancer Staging Manual. 8th ed. New York: Springer (2017).

6. Huang SH, Hwang D, Lockwood G, Goldstein DP, O'Sullivan B. Predictive Value of Tumor Thickness for Cervical Lymph-Node Involvement in Squamous Cell Carcinoma of the Oral Cavity: A Meta-Analysis of Reported Studies. Cancer (2009) 115(7):1489-97. doi: 10.1002/cncr.24161

7. Kane SV, Gupta M, Kakade AC, DC A. Depth of Invasion is the Most Significant Histological Predictor of Subclinical Cervical Lymph Node Metastasis in Early Squamous Carcinomas of the Oral Cavity. Eur J Surg Oncol (2006) 32(7):795-803. doi: 10.1016/j.ejso.2006.05.004

8. Melchers LJ, Schuuring E, van Dijk BA, de Bock GH, Witjes MJ, van der Laan $\mathrm{BF}$, et al. Tumour Infiltration Depth $>/=4 \mathrm{Mm}$ is an Indication for an Elective Neck Dissection in pT1cN0 Oral Squamous Cell Carcinoma. Oral Oncol (2012) 48(4):337-42. doi: 10.1016/j.oraloncology.2011.11.007

9. Pentenero M, Gandolfo S, Carrozzo M. Importance of Tumor Thickness and Depth of Invasion in Nodal Involvement and Prognosis of Oral Squamous Cell Carcinoma: A Review of the Literature. Head Neck (2005) 27(12):108091. doi: 10.1002/hed.20275 
10. Alkureishi LW, Ross GL, Shoaib T, Soutar DS, Robertson AG, Thompson R, et al. Sentinel Node Biopsy in Head and Neck Squamous Cell Cancer: 5-Year Follow-Up of a European Multicenter Trial. Ann Surg Oncol (2010) 17 (9):2459-64. doi: 10.1245/s10434-010-1111-3

11. Civantos FJ, Zitsch RP, Schuller DE, Agrawal A, Smith RB, Nason R, et al. Sentinel Lymph Node Biopsy Accurately Stages the Regional Lymph Nodes for T1-T2 Oral Squamous Cell Carcinomas: Results of a Prospective Multi-Institutional Trial. J Clin Oncol (2010) 28(8):1395-400. doi: 10.1200/JCO.2008.20.8777

12. Govers TM, Hannink G, Merkx MA, Takes RP, Rovers MM. Sentinel Node Biopsy for Squamous Cell Carcinoma of the Oral Cavity and Oropharynx: A Diagnostic Meta-Analysis. Oral Oncol (2013) 49(8):726-32. doi: 10.1016/ j.oraloncology.2013.04.006

13. Broglie MA, Haerle SK, Huber GF, Haile SR, Stoeckli SJ. Occult Metastases Detected by Sentinel Node Biopsy in Patients With Early Oral and Oropharyngeal Squamous Cell Carcinomas: Impact on Survival. Head Neck (2013) 35(5):660-6. doi: 10.1002/hed.23017

14. Pezier T, Nixon IJ, Gurney B, Schilling C, Hussain K, Lyons AJ, et al. Sentinel Lymph Node Biopsy for T1/T2 Oral Cavity Squamous Cell Carcinoma-a Prospective Case Series. Ann Surg Oncol (2012) 19(11):3528-33. doi: 10.1245/ s10434-011-2207-0

15. Samant S. Sentinel Node Biopsy as an Alternative to Elective Neck Dissection for Staging of Early Oral Carcinoma. Head Neck (2014) 36(2):241-6. doi: 10.1002/hed.23288

16. Gentile A, Trusolino L, Comoglio PM. The Met Tyrosine Kinase Receptor in Development and Cancer. Cancer Metastasis Rev (2008) 27(1):85-94. doi: 10.1007/s10555-007-9107-6

17. De Herdt MJ, Koljenovic S, van der Steen B, Willems SM, Wieringa MH, Nieboer D, et al. A Novel Immunohistochemical Scoring System Reveals Associations of C-terminal MET, Ectodomain Shedding, and Loss of Ecadherin With Poor Prognosis in Oral Squamous Cell Carcinoma. Hum Pathol (2020) 104:42-53. doi: 10.1016/j.humpath.2020.07.018

18. Comoglio PM, Trusolino L, Boccaccio C. Known and Novel Roles of the MET Oncogene in Cancer: A Coherent Approach to Targeted Therapy. Nat Rev Cancer (2018) 18(6):341-58. doi: 10.1038/s41568-018-0002-y10.1038/s41568018-0002-y

19. De Herdt MJ, Baatenburg de Jong RJ. HGF and c-MET as Potential Orchestrators of Invasive Growth in Head and Neck Squamous Cell Carcinoma. Front Biosci (2008) 13:2516-26. doi: 10.2741/2863

20. Federa. (2018). Available at: https://www.federa.org/codes-conduct (Accessed November 4, 2020).

21. American Joint Commity on Cancer. Ajcc Cancer Staging Manual. 7th ed. New York: Springer (2010).

22. The Royal College of Pathologists. Dataset for Histopathology Reporting of Mucosal Malignancies of the Oral Cavity (2013). Available at: https://www. rcpath.org/resourceLibrary/dataset-for-histopathology-reporting-ofmucosal-malignancies-of-the-oral-cavity.html.

23. De Herdt MJ, Willems SM, van der Steen B, Noorlag R, Verhoef EI, van Leenders GJ, et al. Absent and Abundant MET Immunoreactivity is Associated With Poor Prognosis of Patients With Oral and Oropharyngeal Squamous Cell Carcinoma. Oncotarget (2016) 7(11):13167-81. doi: 10.18632/oncotarget.7534

24. Brockhoff HC2, Kim RY, Braun TM, Skouteris C, Helman JI, Ward BB. Correlating the Depth of Invasion At Specific Anatomic Locations With the Risk for Regional Metastatic Disease to Lymph Nodes in the Neck for Oral Squamous Cell Carcinoma. Head Neck (2017) 39(5):974-9. doi: 10.1002/ hed. 24724

25. Hutchison IL, Ridout F, Cheung SMY, Shah N, Hardee P, Surwald C, et al. Nationwide Randomised Trial Evaluating Elective Neck Dissection for Early Stage Oral Cancer (SEND Study) With Meta-Analysis and Concurrent RealWorld Cohort. Br J Cancer (2019) 121(10):827-36. doi: 10.1038/s41416-0190587-210.1038/s41416-019-0587-2

26. Massey C, Dharmarajan A, Bannuru RR, Rebeiz E. Management of N0 Neck in Early Oral Squamous Cell Carcinoma: A Systematic Review and MetaAnalysis. Laryngoscope (2019) 129(8):E284-E98. doi: 10.1002/lary.27627

27. Holmstrup P, Vedtofte P, Reibel J, Stoltze K. Oral Premalignant Lesions: Is a Biopsy Reliable? J Oral Pathol Med (2007) 36(5):262-6. doi: 10.1111/j.16000714.2007.00513.x

28. Alsaffar HA, Goldstein DP, King EV, de Almeida JR, Brown DH, Gilbert RW, et al. Correlation Between Clinical and MRI Assessment of Depth of Invasion in
Oral Tongue Squamous Cell Carcinoma. J Otolaryngol Head Neck Surg (2016) 45(1):61. doi: 10.1186/s40463-016-0172-010.1186/s40463-016-0172-0

29. Filauro M, Missale F, Marchi F, Iandelli A, Carobbio ALC, Mazzola F, et al. Intraoral Ultrasonography in the Assessment of DOI in Oral Cavity Squamous Cell Carcinoma: A Comparison With Magnetic Resonance and Histopathology. Eur Arch Otorhinolaryngol (2020). doi: 10.1007/s00405-02006421-w10.1007/s00405-020-06421-w[pii

30. Iida Y, Kamijo T, Kusafuka K, Omae K, Nishiya Y, Hamaguchi N, et al. Depth of Invasion in Superficial Oral Tongue Carcinoma Quantified Using Intraoral Ultrasonography. Laryngoscope (2018) 128(12):2778-82. doi: 10.1002/ lary. 27305

31. Mao MH, Wang S, Feng ZE, Li JZ, Li H, Qin LZ, et al. Accuracy of Magnetic Resonance Imaging in Evaluating the Depth of Invasion of Tongue Cancer. A Prospective Cohort Study. Oral Oncol (2019) 91:79-84. doi: 10.1016/ j.oraloncology.2019.01.021

32. Marchi F, Filauro M, Iandelli A, Carobbio ALC, Mazzola F, Santori G, et al. Magnetic Resonance vs. Intraoral Ultrasonography in the Preoperative Assessment of Oral Squamous Cell Carcinoma: A Systematic Review and Meta-Analysis. Front Oncol (2019) 9:1571. doi: 10.3389/fonc.2019.01571

33. Xu C, Yuan J, Kang L, Zhang X, Wang L, Chen X, et al. Significance of Depth of Invasion Determined by MRI in cT1N0 Tongue Squamous Cell Carcinoma. Sci Rep (2020) 10(1):4695. doi: 10.1038/s41598-020-61474-510.1038/s41598020-61474-5

34. Kumar SS, George NA, Anila KR, Sebastian P. Can Frozen Section be Used to Assess Depth of Invasion of Early Carcinoma of Tongue? Oral Oncol (2015) 51(11):e87-8. doi: 10.1016/j.oraloncology.2015.08.010

35. Moe J, McHugh JB, Udager AM, Braun TM, Helman JI, Ward BB. Intraoperative Depth of Invasion is Accurate in Early-Stage Oral Cavity Squamous Cell Carcinoma. J Oral Maxillofac Surg (2019) 77(8):1704-12. doi: 10.1016/j.joms.2019.02.016

36. Moe J, McHugh JB, Udager AM, O’Brien LM, Ward BB. Comparison of Early Oral Cancer Depth of Invasion From the American Joint Committe on Cancer 7th to 8th Edition Criteria. Does the Difference Impact the Accuracy of Clinical Decision Making? J Oral Maxillofac Surg (2021) 79(4):822-9. doi: 10.1016/j.joms.2020.10.014

37. Arnold L, Enders J, Thomas SM. Activated HGF-c-Met Axis in Head and Neck Cancer. Cancers (Basel) (2017) 9(12). doi: 10.3390/cancers9120169

38. Szturz P, Raymond E, Abitbol C, Albert S, de Gramont A, Faivre S. Understanding c-MET Signalling in Squamous Cell Carcinoma of the Head \& Neck. Crit Rev Oncol Hematol (2017) 111:39-51. doi: 10.1016/j.critrevonc.2017.01.004

39. Galeazzi E, Olivero M, Gervasio FC, De Stefani A, Valente G, Comoglio PM, et al. Detection of MET Oncogene/Hepatocyte Growth Factor Receptor in Lymph Node Metastases From Head and Neck Squamous Cell Carcinomas. Eur Arch Otorhinolaryngol (1997) 254(Suppl 1):S138-43. doi: 10.1007/BF02439745

40. Lo Muzio L, Leonardi R, Mignogna MD, Pannone G, Rubini C, Pieramici T, et al. Scatter Factor Receptor (c-Met) as Possible Prognostic Factor in Patients With Oral Squamous Cell Carcinoma. Anticancer Res (2004) 24(2C):1063-9.

41. Sawatsubashi M, Sasatomi E, Mizokami H, Tokunaga O, Shin T. Expression of c-Met in Laryngeal Carcinoma. Virchows Arch (1998) 432(4):331-5. doi: $10.1007 / \mathrm{s} 004280050174$

42. Cortesina G, Martone T, Galeazzi E, Olivero M, De Stefani A, Bussi M, et al. Staging of Head and Neck Squamous Cell Carcinoma Using the MET Oncogene Product as Marker of Tumor Cells in Lymph Node Metastases. Int J Cancer (2000) 89(3):286-92. doi: 10.1002/1097-0215(20000520) 89:3<286::AID-IJC12>3.0.CO;2-U

Conflict of Interest: The authors declare that the research was conducted in the absence of any commercial or financial relationships that could be construed as a potential conflict of interest.

Copyright ( 2021 De Herdt, van der Steen, van der Toom, Aaboubout, Willems, Wieringa, Baatenburg de Jong, Looijenga, Koljenović and Hardillo. This is an openaccess article distributed under the terms of the Creative Commons Attribution License (CC BY). The use, distribution or reproduction in other forums is permitted, provided the original author(s) and the copyright owner(s) are credited and that the original publication in this journal is cited, in accordance with accepted academic practice. No use, distribution or reproduction is permitted which does not comply with these terms. 